\title{
Traditional management accounting tools in SMEs' network. Do they foster partner dialogue and business innovation?
}

\author{
Selena Aureli ${ }^{*}$ Andrea Cardoni**, Mara Del Baldo ${ }^{* * *}$, \\ Rosa Lombardi ${ }^{* * * *}$
}

Ricevuto il 11 maggio 2018

Accettato l'8 novembre 2018

\begin{abstract}
This paper aims to understand whether traditional management accounting tools (e.g. financial statement, reclassification and contribution margin analysis) contribute to foster dialogue and innovation in business networks composed of SMEs (small and medium-sized enterprises). Through the analysis of a case study, the paper focuses on a contractual network operating in the paper\&print sector in Italy. Framing the analysis in the Simons' construct (1990 and 1995), who distinguishes between diagnostic and interactive controls, the paper provides insights on the use of management control in inter-organizational settings, arguing that the traditional accounting tools can play an innovative role in network success. The contribution of the paper is on the ongoing debate on which functions, accounting information and MCSs (management control systems) may play in networks. In particular, findings shed light on the need to adapt the distinction between "diagnostic" and "interactive" in the network setting, given the horizontal and non-hierarchical relationships between the units involved.
\end{abstract}

Keywords: business innovation, horizontal networks, diagnostic control, interfirm relationships, accounting tools

\footnotetext{
${ }^{*}$ Università di Bologna, Dipartimento di Scienze aziendali. Corresponding author: Tel. +39 0541- 434 230; e-mail: selena.aureli@unibo.it.

${ }^{* *}$ Università degli studi di Perugia, Dipartimento di Economia.

${ }^{* * *}$ Università di Urbino, Dipartimento di Economia, Società e Politica.

*** Università di Roma La Sapienza, Dipartimento di Diritto ed Economia delle Attività Produttive.

The paper is the result of common analysis and the contribution of both authors for each paragraph is of $25 \%$.

One of the authors (Andrea Cardoni) contributed to the paper developing the research project «Strategic Analysis, Management Accounting and Networking for SME's development» supported by the FRB funds of University of Perugia.
}

Management Control (ISSN 2239-0391, ISSNe 2239-4397), 2019, 1 - Special Issue

DOI: 10.3280/MACO2019-SU1003 


\section{Introduction}

Business networks are created to share information, co-produce, co-market and/or co-purchase with the strategic purpose to generate innovation and market development (Håkansson et al., 2009; Cantele et al., 2016). When small and medium-sized enterprises (SMEs) group are directed to create a network altogether, they usually aim to reach the critical dimension to accumulate know-how and bear innovative business development processes (Verschoore et al., 2015; Lin and Lin, 2016) and/or foster internationalization (Lu and Beamish, 2001; Fernhaber and Li, 2013; Aureli and Del Baldo, 2016a). Coherently, networks composed by SMEs need appropriate management control systems (MCSs) to foster knowledge sharing and generation of innovation.

Early studies on management accounting and control considered management control systems (MCSs) as diagnostic controls that formalize routines and aim to stabilize company's processes and control employees, thus limiting the creativity necessary to develop new products (Amabile, 1998; Davila, 2000; Cardinal et al., 2004). On the contrary, recent studies (Davila, 2005; Davila et al., 2009; Chiesa et al., 2009) argued that MCSs can actually enhance innovation thanks to a different - interactive - use of performance measures (Davila et al., 2004). The concept of interactive controls, used in contrast to diagnostic control, was originally developed by Simons (1990 and $1995)^{1}$, while observing management control systems in large corporations. Interactive controls were employed to emphasize the peculiarities of advanced MCSs like target costing and total cost of ownership as tools for information sharing and increased coordination in networks (Baiman and Rajan, 2002; Cooper and Slagmulder, 2004; Lombardi, 2015; Wouters et al., 2005).

Considering that SMEs often group into horizontal networks and may not be willing or prepared to adopt complex tools, the present paper aims to understand whether traditional management accounting tools - such as finan-

${ }^{1}$ Diagnostic Control Systems (DCSs) are "the formal information systems that managers use to monitor organizational outcomes and correct deviations from pre-set standards of performance" (Simons, 1995, p. 59). The key strategic variable underlying a DCS is represented by the critical success factors that have to be monitored. Interactive Control Systems (ICSs) have been defined as "the formal information systems that managers use to personally involve themselves in the decision activities of subordinates" (Simons, 2000, p. 216). In this regard, the underlying strategic variable is strategic uncertainties, since information is used by superiors to challenge the thinking and action plans of subordinates. 
cial statements, reclassification and contribution margin analysis - can contribute to foster dialogue and innovation in networks characterized by equal distribution of coordination roles and resources among partners. Therefore, the research question is:

RQ1: Do traditional management accounting tools contribute to foster partner dialogue and business innovation in networks?

Since traditional management control tools might be used as either diagnostic controls or interactive controls as the distinction relates to how the information is used rather than the technical design feature of the control system (Martyn et al., 2016), the final goal of this paper is to understand which MCSs may help to achieve objectives of innovation in a network composed by SMEs and how they could be leveraged by the network governance.

Accordingly, the present paper focuses on the case study of a contractual network operating in the paper\&print sector, which recorded a continuous growth during the last 10 years and launched some innovative projects but has not implemented any advanced formal strategic management control tools so far. Thanks to document analysis, interviews and direct participation in company meetings, the authors collected information on which management tools have been introduced by the network manager through the years and how he uses them.

The work aims to contribute to the ongoing debate on which functions, accounting information and MCSs may play in interfirm relationships (e.g., Coad and Cullen, 2006; Cuganesan and Lee, 2006; Mahama, 2006; Chua and Mahama, 2007; Thrane, 2007; Caglio and Ditillo, 2012).

With this paper we provide original insights on the use of management control in inter-organizational settings, arguing that the traditional accounting tools can play an innovative role in network success. Moreover, framing the analysis in the Simons' construct, we highlight that the distinction between "diagnostic" and "interactive" in network setting has to be readopted with different characteristics, given the horizontal and non-hierarchical relationships between the units involved.

The remainder of the paper is structured as follows. Section 2 introduces the theoretical framework, while section 3 describes the methodological approach and section 4 illustrates the case study. Finally, sections 5 and 6 respectively discuss the findings and sum up the main insights and conclusive remarks. 


\section{Literature framework: the role and the diagnostic/interactive usage of accounting information and management control systems in net- works}

Early studies on management accounting and control have considered MCSs as systems mainly adopted by managers to formalize routines and procedures, define rules and stabilize company's processes, thus limiting the creativity necessary to develop new products (Amabile, 1998; Davila, 2000). Managers introduce an MCS when they needed formal tools and accounting procedures to control employees in large organizations, where information, communication is not sufficient to guide and control people (Cardinal et al., 2004).

However, recent studies (Davila et al., 2009) highlighted that MCSs can actually enhance innovation and help product development processes in achieving better performance. Even traditional instruments like budgets may contribute to innovation by fostering dialogue, learning and idea creation (Abernathy and Brownell, 1999).

According to Simons' (1995) definition, MCSs are formal, informationbased routines and procedures that managers use to maintain or alter patterns in organizational activities. Thus, whatever information system based on formalized procedures, storing information that influences decision-making and managerial action can be labelled as an MCS. Informal systems such as cultural controls and socialization are excluded from this definition. MCSs do not necessarily have to provide managers with financial data, as qualitative information can be used to maintain or alter organizational activities too ( $\mathrm{Si}$ mons, 2000). However, most studies on management control focus on accounting-based information systems and how managers can use accounting data (Dekker, 2016; Broadbent and Laughlin, 2009; Lukka, 2007; Busco et al., 2007; Burns and Vaivio, 2001).

From the early work of the organization theorist Herbert Simons, accounting information has gained three main functions: to monitor processes and results, to drive attention on specific issues and to facilitate discussion as a mean for solving problems. These roles recur in almost every study on the use of accounting data by company managers (Hall, 2010) and when we look at inter-firm relationships (Caglio and Ditillo, 2012). However, in the case of buyer-supplier networks, the exchange of accounting information can have additional functions. As suggested by Caglio and Ditillo (2012), accounting information contributes to align partners' behaviours to common objectives and consider individual differences that might constrain a partner's involvement to a common project or production process. In other terms, 
accounting information is used to plan a collaborative future with the partners, playing an integrative role across boundaries (Thrane and Hald, 2006) and helping to set reciprocal goal expectations and achievements. In cases of mutual dependence, partners use MCSs to foster optimization of the whole network (Caglio and Ditillo, 2012).

Specific studies concentrate on the usage of cost accounting tools like target costing and total cost of ownership, suggesting that these instruments can be used in networks for additional reasons as to build commitment (Wouters et al., 2005) and increase coordination by creating a trustworthy environment thanks to transparent information sharing (Baiman and Rajan, 2002; Cooper and Slagmulder, 2004). Most of these studies focus on dyadic relationships and conceive MCSs as instruments to control partners and negotiate contract terms, especially in a situation of unilateral dependence. MCSs collect information not to merely report the job done and possible variances from what expected (i.e. the traditional MCS's informative role). They are used by the focal firm to influence partners' behaviour and decisions before acting. In this situation, MCSs are designed to influence the suppliers' activities (Carr and Ng, 1995; Mouritsen et al., 2001) and used by the focal firm to benchmark and select potential suppliers (Mouritsen, 1999).

Recently, two streams of research challenged this opportunistic and functionalist view on MCS's roles. One group of studies (Dekker, 2016; Caglio and Ditillo, 2008) welcomes greater attention to horizontal networks and alliances where there is no focal firm. Focusing on one-side perspective (i.e. those of the supplier or client with stronger decision power) has hindered the understanding of practices used within the collaborative relationship and how these influence the behaviour of managers or employees of all businesses involved in the collaboration. The other group of studies suggests looking at wider functions for MCSs besides making goals explicit and controlling the execution. MCSs may fulfil general purposes in collaborative networks like contributing to knowledge sharing and innovation development or even be used as symbols to legitimize network's activities toward external subjects or the network's board decisions toward the partners (Massaro et al., 2014).

In the past, the authors proposed to use informal controls (i.e. social and behavioral controls) in situations characterized by high uncertainty like interfirm alliances (Das and Teng, 2001) and especially in alliances created to develop new products and processes, with outputs that are difficult to forecast and evaluate (Davila et al., 2009). Nevertheless, since the work of Simons (1995) on the four levers of control, an increasing amount of studies (Meira et al., 2010; Kominis and Dudau, 2012; Massaro et al., 2014; Martyn 
et al., 2016) adopt his framework to highlight the benefits of using MCSs as interactive controls, which means using them to help network partners to focus on strategic uncertainties and then contribute to the formulation of emerging strategies. Simons posits that the use of MCSs in an interactive manner supports managers' capability to handle uncertainty, idea generation and opportunity-seeking behaviour. Thus, his framework has attracted interest from researchers focusing on innovation (Haustein, 2014), especially when innovation is based on knowledge sharing. MCSs may act as tools for knowledge integration (Ditillo, 2004), knowledge creation (Henri, 2006) and also facilitates the generation or re-building of mental models (Hall, 2010).

Following the two critics found in recent contributions, the present paper aims to investigate choices of management control instruments within networks of equal partners and if and how these instruments support the generation of innovative ideas and common projects.

\section{Research Method and Case Study}

We adopted a qualitative research approach, based on a case study research (Yin, 2009) of a contractual network operating in the paper\&print sector (called anonymously the case "A") in Italy. In this regard, single or multiple case study relative to SMEs networks (Ghazali, 2005; Barnes et al., 2012) and contractual networks (Cantele et al., 2016; Trequattrini et al., 2012; Grippo et al., 2015) have been widely used in prior research aimed at deepen issues and features of performance measuring in reticular contexts (Cardoni, 2012; Aureli and Del Baldo, 2016b; Camarinha-Matos et al., 2009; Pekkola, 2013).

To support this research, we used an inductive approach (Flick, 2009) as opposite logic to deductive approach in interpreting reality. The inductive approach is particularly useful to create structures or propositions from the experiences and processes that are included in the data (Grafton et al., 2011). However, inductive reasoning has a great weakness: it is limited. It begins with a single observation or an inference drawn from very specific and alike situations. Thus, generalizations are risky.

We selected the case study based on dimensional criteria, innovativeness of its activities and stability of the network. The case study emerged for its longevity and its structural characteristics, particularly useful for a study on the use of management control systems. In fact, the network " $A$ " was set up in 2007 and currently includes 21 partners, more than 700 collaborators (approximately $8 \%$ of them dedicated to Research and Development) and 24 
production plants successfully operating for more than 10 years. The coordination of the network is facilitated by a limited company, acting as a market development entity in the network. The capital of this limited company is owned by the network partners. Partners' commitment to the network is therefore carried out on two levels: each partner both owns a stock of the limited liability company (an equity-based relationship) and has entered into in the network agreement (a contract-based relationship). One of the main players in the network is an academic spin-off that expressed over time the coordination management team, assuming a leadership role in the development of the collaboration and the promotion of a managerial culture inside the network.

We collected information about the network structure and existing MCSs, focusing on the analysis of current management control systems and performance measurement systems adopted by "A". We used a mix (triangulation) of primary and secondary sources, particularly represented by:

- a questionnaire (Q1) and two semi-structured interviews (IS1, IS2) addressed to the network manager. The network manager is appointed as Chairman of the board of Directors of the coordinating limited company. We focused on this role because it represents the central figure (the socalled key informant person) in the network (Halinen and Törnroos, 2005, p. 1291), having all the information on the network strategic and operational activities and holding the vision of the "whole network" (Provan et al., 2007);

- internal documents including: network contract (ID1), company profile (ID2), product and services catalogue (ID3), financial statements of the coordinating limited company (ID4), network reporting package (ID5), presentations and supporting analysis for partners' general meetings (ID 6), network organizational structure (ID7);

- website and media release: network official website (WM 1).

\section{Findings}

From the documents analysed (ID1, ID2, WM1) and interviews (IS1, IS2), we found the existence of four main strategic goals: i) market development; ii) product innovation; iii) intensification of inter-business activities; iv) R\&D activities. Each objective is monitored through a limited number of performance measures (ID5). Some measures are quantitative (e.g. n. of new products launch), while others are financial indicators (e.g. turnover from foreign customers). In addition, the network manager calculates and reports 
some key financial values and ratios from network's financial statements to the annual assembly of network members (ID6).

Network members are not active participants in the strategic control process (Q1). The network manager is the key responsible for the monitoring process (ID7), having the need to clearly represent the key drivers for success and the causal links between strategy, activity and impacts on performance (ID5).

In order to continuously monitor the fulfilment of strategic goals and share with the partners the advancement toward the results achievement, the governance of the network is based on the elaboration of some traditional management accounting tools (ID5, ID6). All management tools and models found in this case were brought by the university spin-off, which has always been an active partner and also acted as key advisor on the application of managerial approaches (ID5).

The most important MCS adopted is the so-called "annual report" of the network activities. This document is based on the mandatory annual report (ID4) of the coordinating limited company (financial statements plus the notes to the accounts, management report and audit report) integrated with qualitative information on the advancement and results obtained in the four strategic objectives (ID5). It is basically conceived as a management report for internal use, presented in the form of PowerPoint slides and describing some selected metrics of the income statement to show the impact of common activities on the net profit of the case "A". This document is used to report network activities to the assembly at the end of every year, compare results with goals and disclose information to stakeholders, as reported in Q1:

"The main purpose is to inform partners about what has been done together with respect to common goals. In fact, its content is organized according to the same four strategic objectives declared in the network program".

Moreover, it has been used as a learning tool as the network board utilizes it to help network partners reflect on the organizational model of the network itself and transfer some concepts, as the network manager reports (IS1):

"Communicating the results of the annual report is a way to transfer conceptuality, to teach accounting - the language of business - to the smaller partners and induce them reflect on their own financial structure and performance ". 
At the same time, the network manager pointed out that it's a motivator too: it is intended as a stimulus for partners to imitate the behaviour of most active and profitable nodes (IS2):

"By showing (in the report) that three partners succeeded in making a good project and this project generated turnover and profit for the company becomes a stimulus (we wish it) for other partners to propose and share their own ideas and projects with the network. Communicating this result in that way and in that official moment is fundamental”.

Another important control tool used some years ago is the financial statement reclassification performed on the financial data of each network partner. Reclassified statements were also integrated by the calculation of eight key financial measures and indicators on the network's profit and financial structure (ID6). It was used to map the individual members' financial situation and profitability and explain the different characteristics of each partner in financial terms, as highlighted in IS2:

"The reclassification was used to make the partners aware that each company has its own peculiarities, probably with relevant differences, thus we have to listen to each other and understand what partners are able or not to do according to their financial and economic situation. What impressed me is that the partners were not used to interpret their performance in this structured way and they understood very clearly how different their business was in terms of profitability and financial structure".

This accounting information was also used to analyse whether partners were calculating their production costs properly and were able to generate adequate contribution margins. Since it emerged that some partners were miscalculating their margins, this tool became an instrument for partners' strategic orientation when collecting and analysing the proper information to participate to common tender and make their own offer, as reported in IS2:

"This tool was an accounting innovation that established new procedures in data collection and calculation. It was a tool to say that if you want to make a common project, you have to speak like this”. 
Furthermore, traditional project management tools like project schedules and project cards requested by funding entities (e.g. public authorities providing funds for $\mathrm{R} \& \mathrm{D}$ activities) were used or adapted to coordinate common activities referring to both technical and marketing projects (Q1) aimed to develop the network's product and service catalogue (ID3). Schemes, Gantt diagrams and other project management tools were used to formalize the project activities that involve partners and enhance coordination (ID5). When the network applies for a ban, it needs such tools, both in the application phase and at the final stage for technical reasons, but the most valuable aspect is its capability to teach partners some project management concepts and push partners to develop new projects and ideas that can be easily tested in terms of technical and financial feasibility. To this extent the network manager stated (IS1):

\begin{abstract}
"Project schedules are the instrument for innovation management. Even if they might be considered as administrative burdens required by public funding authorities, they bring a great benefit for the network which can the schedule to understand and eventually modify the pre-defined structure of costs, resources and time dedicated to the project".
\end{abstract}

Only in few cases, the above-mentioned instruments played a legitimization role for the network manager, as his leadership role is already acknowledged by all partners on the basis of the governance structure and good performances achieved. Instruments were designed and implemented to create a dialogue among partners with a top-down approach based on managerial and professional concepts considered as the unique way to share objective and strategic on a collaborative setting, as summarized by the network manager (IS2):

"All cited managerial tools have been welcomed by company entrepreneurs and managers, who have specific technical skills but low managerialism propensity. Tools are used to show how things are done in the network, especially when the network members are the typical SMES that manage operations in a destructed manner. Instead, these tools suggest the proper way that things have to be done. They allow you to lead and take leadership of network management without being a technician in $R \& D$ or production aspects". 


\section{Discussion and conclusions}

Based on the network "A" case, we can state that networks composed by SMEs can use traditional accounting tools in an interactive and innovative way. The board of the network, mainly represented by the manager interviewed, has carefully defined the strategic objectives since the creation of the network following a structured approach, which is not usual for similar networks of SMEs (Cardoni, 2012). This facilitated the planning and the selection of proper financial and non-financial indicators that allowed the alignment between the strategic decisions and the control of financial and intangible performance. In addition, thanks to a clear definition of strategic objectives, it has been possible to plan a collaborative future with the partners, playing an integrative role across boundaries (Thrane and Hald, 2006) and helping to set reciprocal goal expectations and achievements.

From a management control perspective, this integrated logic influenced the whole set of reporting tools elaborated by the network manager to comply with institutional and managerial needs like the annual meeting of the assembly.

Performance control has been supported by the following traditional management control tools: the annual report, the reclassification of the partners' financial statements and the analysis of profit and loss account according to the contribution margin criteria. The annual report is not conceived as a mere administrative duty. It is the starting point for creating dialogue and knowledge sharing. Therefore, the creation of the limited liability company participated by network partners helped to both coordinate the network and push partners to take care and develop and expert understanding of financial data. Considering the results achieved by the network in terms of market development, economic and financial performance and innovative projects, the case shows that the traditional accounting tools can play a fundamental role on partner's dialogue and innovation.

Even considering the risks associated with the adoption of frameworks originally developed to describe management controls adopted by single organizations (Caglio and Ditillo, 2008), the case highlights that the traditional accounting tools can be successfully implemented in the examined context.

In this context, the network manager has adopted the managerial control tools to influence partners' behaviour (Carr and Ng, 1995; Mouritsen et al., 2001) as well as to handle uncertainty, idea generation and opportunity-seeking behaviour (Haustein, 2014). In the network " $A$ " case accounting data and key performance indicators have been designed for fostering dialogue about 
strategic objectives and actions and used to both integrate and motivate partners to launch new projects and ideas. While the scorekeeping or informative role of MCS resulted to be weak, figures have been mostly used to develop knowledge beyond specific problems to be solved.

Variance analysis focused on stimuli rather than trying to decipher why things happened. Based on the report structure and contents an important training function can be found, aimed at favouring learning and involvement of the partners whose trust and commitment was perceived as a fundamental asset by the network manager. This contributed to knowledge sharing and innovation development among partners and, in some cases, legitimized network's board decisions toward the partners (Massaro et al., 2014).

According to the network manager, the most important instrument that stimulates network nodes to pull out ideas was the annual report (ID4) and the annual reporting package (ID5). As clearly expressed by his words (IS2):

\section{"It should be understood that network's innovations originate from one or few more dynamic companies (i.e. an entrepreneur has an idea that shares with others). Thus, it is fundamental to foster dialogue and share ideas with no fears of being stolen".}

The presentation of the annual report and its discussion with all partners have been capable to foster dialogue and encourage firms to share their knowledge. This did not happen before creating the network, even though entrepreneurs knew each other directly. They did not find the time to meet and share ideas, nor did they feel comfortable to do it without the network agreement. For example, a couple of years ago an entrepreneur took part at a conference and come back with the idea of making a compostable label. However, this idea was out of business capabilities and technical knowledge. Then, he shared the idea with the network manager who started to search for the right partners within the network. The entrepreneur found the appropriate partners to translate his idea into reality without fearing that intellectual property could be stolen.

In the light of Simons' work $(1990 ; 1995)$, the network "A" case suggests the need to adapt the framework in the network settings. In the case of intrafirm management control, the diagnostic use implies a top-down, one-way logic, and the performance measurement of the operational results serves as a mechanism for monitoring the implementation of the strategy. Vice versa, in the interactive use, performance measurement creates a moment of knowledge sharing and dialectic between operational staff and management as a fundamental step for the strategy formulation. 
Despite being an engineered and structured network, the network " $A$ " case shows that the distinction between "diagnostic" and "interactive" in network setting has to be readopted with different characteristics. Given the horizontal and non-hierarchical relationships between the units involved, the diagnostic use is reticular and more directed to legitimize the network's leadership on demonstrating to the partners that the network results are fulfilled. On the other hand, the interactive use is devoted to the stimulus of ideas and knowledge sharing to form a professional and managerial culture of collaboration. According to this perspective, we can conclude that the use of traditional managerial tools in network " $\mathrm{A}$ " has been interactive, contributing significantly to the development of the network and its strategic and operational results.

As the present paper is the result of the application of a single case study methodology, in some scholars' point of view, the findings and the remarks proposed in it have to be considered in the light of the limitation related to the external validity and generalizability of a single case. Particularly, the results of the study could have been influenced by the specific features of the case selected, including the extension of the network in terms of partners involved, the engineered organizational and contractual structure, and the leading role played by the academic spin-off and the network manager.

\section{References}

Abernathy M., Brownell P. (1999), The role of budgets in organizations facing strategic change: An exploratory study, Accounting, Organizations and Society, Vol. 24, No. 3, pp. 189-204.

Amabile T.M. (1998), How to kill creativity, Harvard Business Review, Vol. 76, pp. 77-87.

Aureli S., Del Baldo M. (2016a), Formal Inter-Firm Cooperation and International Expansion: How Italian SMEs are Using the Network Contract. In: Etemad H., Denicolai S., Hagen B., Zucchella A. (ed), The Changing Global Economy and its Impact on International Entrepreneurship. The McGill International Entrepreneurship series, Edward Elgar Publishing, Cheltenham, UK, pp. 157-182. DOI: 10.4337/9781783479849.00014.

Aureli S., Del Baldo M. (2016b), Performance Appraisal of Business Networks. How Small and Medium Enterprises Define and Monitor Network Objectives, Management Control, Vol. 1, pp. 35-58. DOI: 10.3280/MACO2016-001003.

Baiman S., Rajan M.V. (2002), The role of information and opportunism in the choice of buyer-supplier relationships, Journal of Accounting Research, Vol. 40, pp. 247-278.

Barnes D., Clear F., Dyerson R., Harindranath G., Harris L., Rae A. (2012), Web 2.0 and micro-businesses: an exploratory investigation, Journal of Small Business and Enterprise Development, Vol. 19 No. 4, pp. 687- 711.

DOI: $10.1108 / 14626001211277479$.

Broadbent J., Laughlin R. (2009), Performance management systems: A conceptual model, Management Accounting Research, Vol. 20, pp. 283-295. 
Burns J., Vaivio J. (2001), Management accounting change, Management Accounting Research, Vol. 12, pp. 389-402.

Busco C., Quattrone P., Riccaboni A. (2007), Management accounting: issues in interpreting its nature and change, Management Accounting, Research, Vol. 18, pp. 125-149.

Caglio A., Ditillo A. (2012), Interdependence and accounting information exchanges in interfirm relationships, Journal of Management and Governance, Vol. 16, pp. 57-80.

Caglio A., Ditillo A. (2008), A review and discussion of management control in inter-firm relationships: Achievements and future directions, Accounting, Organizations and Society, Vol. 33, pp. 865-898.

Cantele S., Vernizzi S., Ricciardi F. (2016), The emerging wave of agility-oriented business networks in Italy: a new strategy for facing global competition, World Review of Entrepreneurship, Management and Sustainable Development, Vol. 12, No. 2/3, pp. 270-284. DOI: 10.1504/WREMSD.2016.074967.

Camarinha-Matos L.M., Afsarmanesh H., Galeano N., Molina A. (2009), Collaborative networked organizations - concepts and practice in manufacturing enterprises, Computers \& Industrial Engineering, Vol. 57 No. 1, pp. 46-60.

Cardinal L.B., Sitkin S.B., Long C.P. (2004), Balancing and rebalancing in the creation and evolution of organizational control, Organization Science, Vol. 15, No. 4, pp. 411-431.

Cardoni A. (2012), Business planning and management accounting in strategic networks: theoretical development and empirical evidence from enterprises' network agreement, Management Control, Vol. 3, pp. 91-116.

DOI: 10.3280/MACO2013-SU3005

Carr C., Ng J. (1995), Total cost control: Nissan and its UK supplier partnerships, Management Accounting Research, Vol. 6, pp. 347-365.

Chiesa V., Frattini F., Lamberti L., Noci G. (2009), Exploring management control in radical innovation projects, European Journal of Innovation Management, Vol. 12, No. 4, pp. 416-443.

Coad A.F., Cullen J. (2006), Inter-organisational cost management: Towards an evolutionary perspective, Management Accounting Research, Vol. 17, No. 4, pp. 342-369.

Cuganesan S., Lee R. (2006), Intra-organisational influences in procurement networks controls: The impacts of information technology, Management Accounting Research, Vol. 17, No. 2, pp. 141-170.

Chua W. F., Mahama H. (2007), The effect of network ties on accounting controls in a supply alliance: field study evidence, Contemporary Accounting Research, Vol. 24, No. 1, pp. 47-86.

Cooper R., Slagmulder R. (2004), Interorganizational cost management and relational context. Accounting, Organizations and Society, Vol. 29, pp. 1-26.

Das T.K., Teng B.S. (2001), Trust, control, and risk in strategic alliances: An integrated framework, Organization Studies, Vol. 22, No. 2, pp. 251-283

Davila T., Epstein M. J., Matusik F. (2004), Innovation strategy and the use of performance measures, Advances in Management Accounting, Vol. 13, pp. 27-58.

Davila A., Foster G., Li M. (2009), Reasons for management control systems adoption: Insights from product development systems choice by early-stage entrepreneurial companies, Accounting, Organizations and Society, Vol. 34, pp. 322-347.

Davila T. (2000), An empirical study on the drivers of management control systems' design in new product development, Accounting, Organizations and Society, Vol. 25, pp. 383409. 
Davila T. (2005), The Promise of Management Control Systems for Innovation and Strategic Change, in C.S. Chapman (ed.), Controlling Strategy, Oxford: Oxford University Press, pp. 37-61.

Dekker H. (2016), On the boundaries between intrafirm and interfirm management accounting research, Management Accounting Research, Vol. 31, pp. 86-99.

Ditillo A. (2004), Dealing with uncertainty in knowledge-intensive firms: the role of management control systems as knowledge integration mechanisms, Accounting, Organizations and Society, Vol. 29, pp. 401-421.

Fernhaber S., Li D. (2013) International exposure through network relationship: implication for new venture internationalization, Journal of Business Venturing, Vol. 28 No. 2, pp. 316-334. DOI: 10.1016/j.jbusvent.2012.05.002.

Flick U. (2009), An introduction to qualitative research, Sage, London, UK.

Ghazali A. (2005), Small firm Owner-managers' networks in Tourism and Hospitality, International Journal of Business and Society, Vol. 6, No. 2, pp. 37-54.

Grafton G., Lillis A.M., Mahama H. (2011), Mixed methods research in accounting, Qualitative Research in Accounting \& Management, Vol. 8, no. 1, pp. 5-21.

Grippo G., Marchiori M., Tunisini A. (2016), Lo start up delle reti tra imprese. Analisi dei gap tra intenzione e interazione, Piccola Impresa/Small Business, Vol. 2, pp. 5-25. DOI: 10.14596/pisb.247.

Håkansson H., Ford D., Gadde L.E., Shenota I., Waluszewski A. (2009), Business in Network, John Wiley \& Son Ltd, New York.

Halinen A., Törnroos J.A. (2005), Using case methods in the study of contemporary business networks, Journal of Business Research, Vol. 58, No. 9, pp. 1285-1297.

Hall M. (2010), Accounting information and managerial work, Accounting, Organizations and Society, Vol. 35, pp. 301-315.

Haustein E. (2014), Management control systems in innovation companies: a literature based framework, Journal of Management Control, Vol. 4, pp. 343-382. DOI: 10.1007/s00187014-0187-5.

Henri J.F. (2006), Management Control systems and strategy: a resource-based perspective, Accounting, Organizations and Society, Vol. 31, No. 6, pp. 529-558.

Kominis G., Dudau A.I. (2012), Time for interactive control systems in the public sector? The case of every child matters policy change in England, Management Accounting Research, Vol. 23, pp. 142-155.

Lin F., Lin Y. (2016), The effect of network relationship on the performance of SMEs, Journal of Business Research, Vol. 69, No. 5, pp. 1780-1784. DOI: 10.1016/j.jbusres.2015.10.055.

Lombardi R. (2015), Le reti d'impresa in economia aziendale. Profili critici e interpretativi, Giappichelli, Torino.

Lu J., Beamish P. (2001), The internazionalisation and performance of SMEs, Strategic Management Journal, Vol. 22, No. 6-7, pp. 565-586.

DOI: $10.1002 /$ smj. 184 .

Lukka K. (2007), Management accounting change and stability: loosely coupled rules and routines in action, Management Accounting Research, Vol. 18, pp. 76-101.

Mahama H. (2006), Management control systems, cooperation and performance in strategic supply relationships: a survey in the mines, Management Accounting Research, Vol. 17, No. 3, pp. 315-339. DOI: 10.1016/j.mar.2006.03.002.

Martyn P., Sweeney, B., Curtis E., (2016), Strategy and control: 25 years of empirical use of Simons' Levers of Control framework, Journal of Accounting \& Organizational Change, Vol. 12, No 3, pp. 281-324. 
Massaro M., Zanin F., Bardy R. (2014), Levers of control and knowledge sharing in alliances among large firms and small firms in the pharmaceutical industry, Management Control, Vol. 2, pp. 117-138.

Meira J., Kartalis N.D., Tsamenyi M., Cullen J. (2010), Management controls and inter-firm relationship: a review, Journal of Accounting \& Organizational Change, Vol. 6, No. 1, pp. 149-169.

Mouritsen J. (1999), The flexible firm: Strategies for a subcontractor's management control. Accounting, Organizations and Society, Vol. 24, pp. 31-55.

Mouritsen J., Hansen A., Hansen C.Ø. (2001), Interorganizational controls and organizational competencies: Episodes around target cost management/functional analysis and open book accounting, Management Accounting Research, Vol. 12, pp. 221-244.

Pekkola S. (2013b), Managing a network by utilizing performance measurement information, Measuring Business Excellence, Vol. 17, No. 1, pp. 72- 79.

Provan K.G., Fish A., Sidow J. (2007), Interorganizational Networks at the Network Level: A Review of the Empirical Literature on Whole Networks, Journal of Management and Governance, Vol. 33, N. 6, pp. 479-516. DOI: 10.1177/0149206307302554.

Simons R. (1995), Levers of Control. How Managers Use Innovative Control System to Drive Strategic Renewal, Boston, MA, Harvard Business School Press.

Simons R. (1990), The role of management control systems in creating competitive advantage: New Perspectives. Accounting, Organizations and Society, Vol. 15, No. 1/2, pp. 127-143.

Simons R. (2000), Performance measurement and control systems for implementing strategy: text \& cases, Upper Saddle River, NJ, Prentice Hall.

Trequattrini R., Russo G., Lombardi R. (2012), Network Governance: Organizational and Legal Profiles, Corporate Ownership \& Control, Vol. 9, No. 4, pp. 346-350. DOI: $10.22495 /$ cocv9i4c3art5.

Thrane S., Hald K.S. (2006), The emergence of boundaries and accounting in supply fields: The dynamics of integration and fragmentation, Management Accounting Research, Vol 17, No. 3, pp. 288-314.

Thrane S. (2007), The complexity of management accounting change: Bifurcation and oscillation in schizophrenic inter-organisational systems, Management Accounting Research, Vol. 18, No. 2, pp. 248-272.

Verschoore J.R., Wegner D., Balestrin A. (2015), The evolution of collaborative practices in small-firm networks: a qualitative analysis of four Brazilian cases, International Journal of Management Practice, Vol. 8, No. 2, pp. 152-168.

DOI: 10.1504/IJMP.2015.071691

Wouters M., Anderson J.C., Wynstra F. (2005), The adoption of total cost of ownership for sourcing decisions - a structural equation analysis, Accounting, Organizations and Society, Vol. 30, pp. 167-191.

Yin R.K. (2009), Case study research - design and methods, $4^{\text {th }}$ ed. Sage Publications, Newbury Park, CA. 